\title{
Ordenamento florestal por talhões: metodologia apoiada em SIG e silvicultura para o manejo de florestas nativas
}

\author{
Jéssica Caroline Maran $\oplus^{1 *}$ Maria Augusta Doetzer Rosot $0^{2}$ Afonso Figueiredo Filho $\oplus^{3}$ André \\ Eduardo Biscaia de Lacerda ${ }^{2}$
}

${ }^{1}$ Universidade Federal do Paraná, Av. Pref. Lothário Meissner, 632, Jardim Botânico, Campus III, CEP 80210-170, Curitiba, PR, Brasil ${ }^{2}$ Empresa Brasileira de Pesquisa Agropecuária - Florestas, Estrada da Ribeira, Km 11, CEP 83411-000, Colombo, PR, Brasil ${ }^{3}$ Universidade Estadual do Centro Oeste, R. Prof. Maria Rosa Zanon de Almeida, Engenheiro Gutierrez, CEP 84505-677, Irati, PR, Brasil

\begin{abstract}
Original Article
*Corresponding author: jess.maran@gmail.com

Palavras-chave:

Subtipologias

Floresta com Araucária

Talhonamento

Keywords:

Sub-typologies

Araucaria Forest

Forest Stratification

Received in

2019/05/16

Accepted on

2020/05/07

RESUMO: A conservação dos remanescentes de Floresta Ombrófila Mista (FOM) representa um grande desafio, mas com potencial de redução dos níveis de desmatamento à medida que o manejo sustentável dos seus recursos é estimulado. No entanto, a realização de pesquisas sobre o tema não tem sido incentivada, principalmente em função das atuais restrições legais. Nesse sentido, esse trabalho apresenta a metodologia de ordenamento florestal por talhões, técnica amplamente utilizada com êxito na Europa Central, aplicada à FOM, tendo como área de estudo a Estação Experimental da Embrapa em Caçador - SC. A metodologia proposta envolveu duas etapas principais: a divisão territorial e a descrição e definição de técnicas silviculturais gerais. Como resultado, caracterizaram-se áreas de uso restrito para o manejo florestal e seis subtipologias distintas, que foram agrupadas em quatro unidades silviculturais (floresta com araucária; floresta estruturada; floresta degradada e vegetação de solos úmidos). As subtipologias mapeadas e descritas neste trabalho representam as mesmas variações que ocorrem ao longo do território ocupado pela FOM, de forma que os regimes silviculturais gerais apresentados também podem ser aplicados em áreas com características similares. Entre os regimes silviculturais propostos encontram-se intervenções pelo método de seleção, cortes de melhoramento, plantios de adensamento e de enriquecimento, raleio de espécies pioneiras, controle da taquara e coleta de produtos florestais não-madeireiros. A metodologia aqui apresentada pode dar suporte na tomada de decisões no que se refere à gestão da propriedade rural, visando, principalmente, o uso e conservação dos remanescentes florestais.
\end{abstract}

Published in

2020/06/30

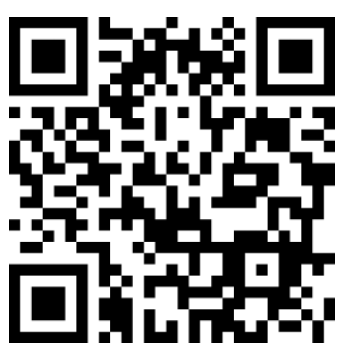

DOI:

https://doi.org/10.34062/afs. v7i 2.8379

\section{(cc) BY}

\section{Forest management by stands: GIS and forestry based methodology for the management of native forests}

\begin{abstract}
The conservation of Ombrophylous Mixed Forest (OMF) remnants presents a great challenge, although with the potential to reduce deforestation through the sustainable management of its resources. However, research on the subject has not been encouraged, mainly due to the current legal restrictions. The objective of this paper was to apply to the OMF the methodology of forest management by stands, a successful technique used widely in Central Europe, with the Embrapa Research Station in Caçador - SC used as the study area. The methodology involved two main steps: territorial division and description and definition of general silvicultural techniques. As a result, areas of restricted use for forest management were characterized, as well as six distinct sub-typologies, grouped into four silvicultural units (forest with araucaria; structured forest; degraded forest; and wet soils vegetation). The mapped and described subtypologies represent the same variations that occur throughout the OMF territory, and as such these general silvicultural regimes can be applied in areas with similar characteristics. Among the proposed silvicultural regimes are interventions by selective cutting, improvement cutting, densification and enrichment, control of bamboo, and collection of nontimber forest products. Thus, this methodology may support decision making processes regarding the management of rural properties.
\end{abstract}


Introdução

O manejo florestal sustentável constitui uma alternativa importante para reduzir o desmatamento, conferindo valor à floresta bem conservada (Basso 2010; Hess et al. 2010; Venturoli et al. 2015; Longhi et al. 2018) e proporcionando sua manutenção enquanto recurso capaz de gerar renda por prazo indeterminado. Ao equilibrar produtividade e conservação da biodiversidade, as funções ecológicas da floresta são mantidas, permitindo a continuidade dos seus benefícios sociais e econômicos, em várias escalas (Nasi e Frost 2009).

Todavia, no Brasil predomina uma visão quase que exclusivamente preservacionista sobre os ecossistemas florestais (Piazza et al. 2017). Sob essa perspectiva, a publicação da Resolução $n^{\circ} 278$, de 24 de maio de 2001 (Conama 2001), vedou todo e qualquer aproveitamento comercial de diversas espécies presentes na Floresta Ombrófila Mista (FOM), além de suspender os planos de manejo florestal que se encontravam em execução na sua área de abrangência.

Ainda que se tenha observado uma queda de $52 \%$ nos desflorestamentos ocorridos na Mata Atlântica no Paraná entre 2016 e 2017, o centro-sul do Estado (uma das regiões de maior concentração da FOM) segue apresentando crescimento nas taxas de degradação (Fundação SOS Mata Atlântica 2018). O desmatamento e a conversão do uso do solo para agricultura ou pecuária na FOM são as práticas mais comuns (Rosot 2007; Fantini et al. 2016), conduzindo à perda permanente de habitat florestal (Fantini et al. 2016).

A garantia de que as ações de manejo possibilitem a melhoria da floresta em termos de estrutura, florística, manutenção da capacidade de reprodução e perpetuação das espécies, além de ordenar os recursos florestais de forma a atingir uma produção com rendimento sustentado depende, fundamentalmente, da adoção de métodos de ordenamento florestal (Rosot 2007).

O ordenamento pode ser definido como um sistema de organização da área florestal e, consequentemente, de sua regeneração, que tem como objetivo principal assegurar a perpetuidade da floresta respondendo onde, como, quanto e quando devem ser aplicados determinados tratamentos silviculturais em uma unidade de manejo florestal (Molina et al. 2011).

$\mathrm{Na}$ Amazônia Legal - onde é permitida a exploração madeireira de florestas naturais - os métodos empregados se baseiam na elaboração e execução de um Plano de Manejo Florestal Sustentável, que, entretanto, não contemplam a aplicação de tratamentos silviculturais sítioespecíficos em diferentes locais e períodos. Tal fato se deve, principalmente, à dificuldade e, mesmo, inviabilidade econômica, para a condução da floresta, considerando as características particulares das tipologias encontradas na Amazônia, bem como problemas de acesso e infraestrutura.

O método de ordenamento por talhões tem sua origem histórica nos trabalhos publicados por Friedrich Judeich entre 1871 e 1893, na Alemanha (Molina et al. 2011; Grau e Nicolau 2007). Após uma evolução notável por meio de reformulações e adaptações, especialmente aquelas introduzidas por Speidel em 1893, está sendo aplicado com êxito em toda a Europa Central, notadamente na Espanha (Rodríguez et al. 2004; Grau e Nicolau 2007; 2008; Comunidad de Madrid 2010; Sánchez-Palencia et al. 2011; Alboreca 2016; Romero 2016), tendo como objetivo principal a produção de madeira, em sítios com vocação para tal. Em espaços naturais protegidos, tais como a Red Natura 2000 (EUROPARC-España, 2013), outras funções e objetivos são priorizados.

Em uma abordagem ampla do contexto de manejo florestal sustentável, a Empresa Brasileira de Pesquisa Agropecuária (Embrapa) - unidade Florestas - desenvolve, atualmente, o projeto "Uso e conservação da Araucária na agricultura familiar", que visa disponibilizar e sistematizar técnicas de manejo florestal e de sistemas de produção sustentáveis para a conservação da FOM. No âmbito do projeto da Embrapa Florestas, objetiva-se definir e organizar uma sequência de procedimentos apoiados por Sistema de Informações Geográficas que permita a aplicação futura do método de ordenamento florestal por talhões a remanescentes da Floresta com Araucária. A descrição de tais procedimentos, tendo como estudo de caso um fragmento de Floresta Ombrófila Mista, constitui o objeto do presente trabalho.

\section{Materiais e Métodos}

Caracterização da área de estudo

A área de estudo é representada pela Estação Experimental da Embrapa em Caçador (EEEC), localizada na região centro-oeste do estado de Santa Catarina, entre as coordenadas geográficas $50^{\circ} 05^{\prime} \mathrm{e}$ $51^{\circ} 00^{\prime}$ de Longitude Oeste de Greenwich e de $26^{\circ} 50^{\prime}$ e $26^{\circ} 55^{\prime}$ de Latitude Sul.

Abrange uma área de 1.197 hectares, sendo 94\% ocupados pela tipologia "Floresta Ombrófila Mista Montana”, e, o restante, por áreas agrícolas, corpos d’água e infraestrutura. Sua cobertura florestal varia quanto à estrutura e composição florística devido às diferenças ocasionadas por componentes ecológicos e antropogênicos, apresentando diferentes feições fitofisionômicas, compostas por remanescentes primários alterados e florestas secundárias, em diversos estágios sucessionais. 


\section{Base cartográfica}

A área de estudo possui base cartográfica confeccionada a partir da digitalização manual de uma carta topográfica do município de Caçador, elaborada pela Diretoria de Serviços Geográficos (DSG) (folha SG-22-Z-A-IV-3), em escala 1:50.000. As informações obtidas de tal carta correspondem à vetorização da hidrografia, rede viária, pontos cotados e curvas de nível.

Além dessa base, utilizou-se duas imagens de alta resolução provenientes do satélite WorldView2, sendo uma pancromática, com resolução espacial de 0,5 metro, e uma multiespectral, com resolução espacial de 2 metros, composta por oito bandas espectrais. Ambas ortorretificadas, obedecendo ao Padrão de Exatidão Cartográfica (PEC) dentro da classe A. As imagens possuem resolução radiométrica de 11 bits/pixel e um ângulo máximo de coleta de $30^{\circ}$ off-nadir.

\section{Divisão territorial}

Em termos gerais, a metodologia envolve desde o estabelecimento de critérios para o talhonamento da floresta, apoiado por Sistema de Informações Geográficas (SIG), bem como a descrição de talhões-tipo e a definição de técnicas silviculturas gerais, por unidade silvicultural, considerando os objetivos do manejo e aptidão de cada talhão.

No método de ordenamento florestal por talhões, a superfície florestal a ser ordenada é dividida em unidades territoriais progressivamente menores. Adaptando-se esse método para a realidade das florestas e/ou propriedades da região sul do Brasil, tem-se as unidades de divisão territorial propostas conforme apresentadas na Tabela 1. Para a EEEC, a primeira unidade de divisão territorial permanente é representada por toda a área abrangida pela propriedade (equivalendo ao termo cuartel, empregado no original espanhol).

Tabela 1. Unidades de divisão territorial adotadas no método de ordenamento por talhões

\begin{tabular}{|c|c|c|}
\hline Tipo de divisão & & Unidade \\
\hline & Propriedade & $\begin{array}{l}\text { Grandes unidades de área, correspondendo à propriedade (500 a } 1.000 \\
\text { ha). Subdividem-se em Subtipologias florestais. }\end{array}$ \\
\hline Permanente & $\begin{array}{l}\text { Subtipologia } \\
\text { florestal }\end{array}$ & $\begin{array}{l}\text { Unidade territorial homogênea em termos de composição de espécies, } \\
\text { estágios sucessionais, características ecológicas e silvicultura a } \\
\text { aplicar, com limites facilmente identificáveis e distinguíveis em } \\
\text { relação a outras subtipologias. Área variável. Pode estar subdividida } \\
\text { em Talhões. }\end{array}$ \\
\hline Temporária & Talhão & $\begin{array}{l}\text { Unidades territoriais temporárias, definidas em cada ordenamento } \\
\text { segundo as características da floresta ou outras variáveis (rios, } \\
\text { estradas, zonas com restrições de uso). Sua forma e extensão podem } \\
\text { variar de ordenamento a ordenamento segundo a evolução da floresta. } \\
\text { Têm sua origem nas subtipologias e nos limites físicos como rios e } \\
\text { estradas da propriedade. }\end{array}$ \\
\hline
\end{tabular}

Fonte: Adaptado de Molina et al. (2011).

\section{Subtipologias}

A segunda unidade de divisão territorial permanente corresponde às unidades homogêneas de mapeamento (cantones), aqui descritas e identificadas como subtipologias. A definição das subtipologias foi realizada por meio da interpretação visual da imagem WorldView-2, a partir da composição colorida R8G6B3, no software QGIS2.6, por meio da digitalização manual em tela das feições poligonais.

Estruturou-se o mapeamento da área em dois níveis hierárquicos: o primeiro, referente aos estágios sucessionais da vegetação (vegetação secundária em estágio inicial, médio ou avançado de regeneração) e; o segundo, quanto às diferentes subtipologias presentes na área, uma vez que, se entende que composições específicas de espécies distintas requerem diferentes abordagens na sua análise (Kellermann 2011), ainda que pertencentes a um mesmo estágio sucessional.

Os níveis hierárquicos e as subtipologias foram estratificados considerando a presença de espécies características de cada estágio sucessioal, com fisionomia arbórea, que formam o dossel da floresta. Subdividiu-se a área de estudo de acordo com parâmetros de textura, resposta espectral e de composição florística, identificados na imagem WorldView-2 e em campo. Para a análise e definição dos estágios de sucessão da vegetação presentes na área de estudo foi utilizada, ainda, a Resolução do Conama, $n^{\circ} 10$ de 1993 (Conama 1993).

Como dados de apoio, foram utilizadas informações oriundas de parcelas de inventário (Herrera et al. 2009), dados de parcelas permanentes presentes na área de estudo com informações do período de 2004 a 2013 (Beckert et al. 2014) e 
informações coletadas em campo para validação do mapeamento.

\section{Unidades Silviculturais}

Unidades Silviculturais (US) são superfícies da floresta onde se aplicam as mesmas ações silviculturais (Cochmanski 2015). Assim, subtipologias com padrão estrutural e características próximas e que, portanto, podem receber as mesmas prescrições silviculturais de caráter geral, sendo agrupadas em diferentes US.

Os regimes silviculturais a serem aplicados em cada talhão são compostos com base nos regimes silviculturais gerais para a formação vegetal presente nas US, acrescidos das particularidades que requeira a gestão de cada talhão em função de sua situação atual, das necessidades detectadas durante $\mathrm{o}$ talhonamento, e dos objetivos e condicionantes do manejo (Gotarredona e Garcia 2008).

Com base nessas premissas foram descritos tratamentos silviculturais gerais para cada US, adaptados de métodos da literatura, partindo de um modelo mais simples, considerando-se os atributos de cada US.

\section{Talhonamento}

Os talhões (rodales) foram originados a partir do cruzamento dos polígonos correspondentes às subtipologias, redes hidrográfica e viária da propriedade, em ambiente SIG. Foram incluídas neste processo, áreas com características restritivas à aplicação do manejo florestal, denominadas "Zonas com Restrições Legais de Uso" (representadas pelas Áreas de Preservação Permanente (APP) e Reserva Legal (RL)), e "Zonas com Restrições Operacionais de Uso" (áreas destinadas ao desenvolvimento de outras pesquisas).

Polígonos com área menor do que um hectare foram agregados aos talhões adjacentes, visando a obtenção de talhões com área mínima de um hectare, para fins operacionais. Para tanto, considerou-se o estágio de desenvolvimento da vegetação, agregando-se apenas aqueles que pudessem receber os mesmos tratamentos silviculturais.

\section{Resultados e discussão}

A técnica empregada para o mapeamento das subtipologias possibilitou sua separação nas seguintes classes homogêneas:

Floresta em estágio inicial de regeneração natural - (1) Associação bracatinga/vassoura: áreas de dominância da espécie pioneira Mimosa scabrella Benth., com presença de Piptocarpha angustifolia Dusén ex Malme e Vernonanthura discolor (Spreng.) H.Rob. Correspondem às florestas que sofreram exploração madeireira intensa e/ou foram impactadas por incêndios florestais, o que reduziu fortemente seus níveis de biomassa e volume. Da mesma maneira que, alterou significativamente a sua estrutura e composição florística, criando condições para a dominância de Merostachys skvortzovii Send., sendo comuns, também, indivíduos do gênero Chusquea spp. (Kellermann 2011). Em campo, o que se observa são agrupamentos contínuos e densos desses indivíduos cobrindo o sub-bosque de tal subtipologia, entremeados por estas espécies pioneiras arbóreas que compõem um dossel aberto. Essa composição é refletida na imagem por um padrão homogêneo, devido a predominância de uma única espécie, coloração amarelo vivo e textura fina; Floresta em estágio médio de regeneração natural - (2) Associação camboatá/canelas: diversidade biológica significativa, quando comparada à de estágio inicial, onde se observa a formação de mais de um estrato, compostos predominantemente por Cupania vernalis Cambess. e Ocotea puberula (Rich.) Nees, além de outras espécies classificadas como indicadoras do estágio médio de regeneração natural (Conama 1994ab). Tal heterogeneidade pode ser constatada na resposta espectral pela variação de cores que vão do amarelo para diferentes tons de cinza;

Floresta em estágio avançado de desenvolvimento - (3) Canelas: corresponde às áreas de ocorrência de exemplares remanescentes da espécie Ocotea porosa (Nees \& Mart.) Barroso e outras do mesmo gênero, entre elas Ocotea pulchella (Nees \& Mart.) Mez. Na imagem satelitária é identificada por uma coloração mesclada em tons de marrom a amarelo, com pontuações em tons azulados, apresentando textura grosseira; (4) Predominância de araucária: preponderância da espécie Araucaria angustifolia (Bertol.) Kuntze no dossel superior da floresta. Resposta espectral mais homogênea, devido ao predomínio da araucária no dossel, o que proporciona uma textura rugosa para a imagem, e um padrão bastante característico formado pelas copas da espécie dominante; (5) Baixa densidade de araucária: é possível distinguir a presença de dois estratos: um superior, formado pela presença de vários indivíduos de Araucaria angustifolia, e o outro, com características semelhantes ao observado na subtipologia “ (3) Canelas";

Vegetação em estágio não definido - (6) Vegetação de solos úmidos: vegetação arbustiva que se desenvolve sobre solos com umidade elevada, onde o afloramento do lençol freático e o nível de hidromorfismo não são extremos;

A resposta espectral de cada subtipologia, tal como observada na imagem WorldView-2, é mostrada na Tabela 2, juntamente com a foto panorâmica terrestre da vegetação correspondente na área de estudo. Na Tabela 3 é apresentado o número de árvores por hectare para cada uma das subtipologias mapeadas, de acordo com os dados auxiliares utilizados.

Além das subtipologias descritas, também foram mapeadas áreas de várzea, corpos d'água, estradas, solo exposto, área de 
Maran et al.

agricultura/fruticultura e áreas construídas. No total foram mapeados 248 polígonos (Tabela 4), com o maior número de polígonos pertencentes à subtipologia (1) "Associação bracatinga/vassourão", concentrados principalmente na região Leste da
EEEC. Esta área foi a que mais sofreu exploração no passado, encontrando-se, ainda, estagnada em estágio inicial de sucessão natural.

Tabela 2. Resposta espectral observada na imagem WorldView-2 (composição colorida R8G6B3), e respectiva foto panorâmica terrestre, para as diferentes subtipologias florestais mapeadas na área de estudo.

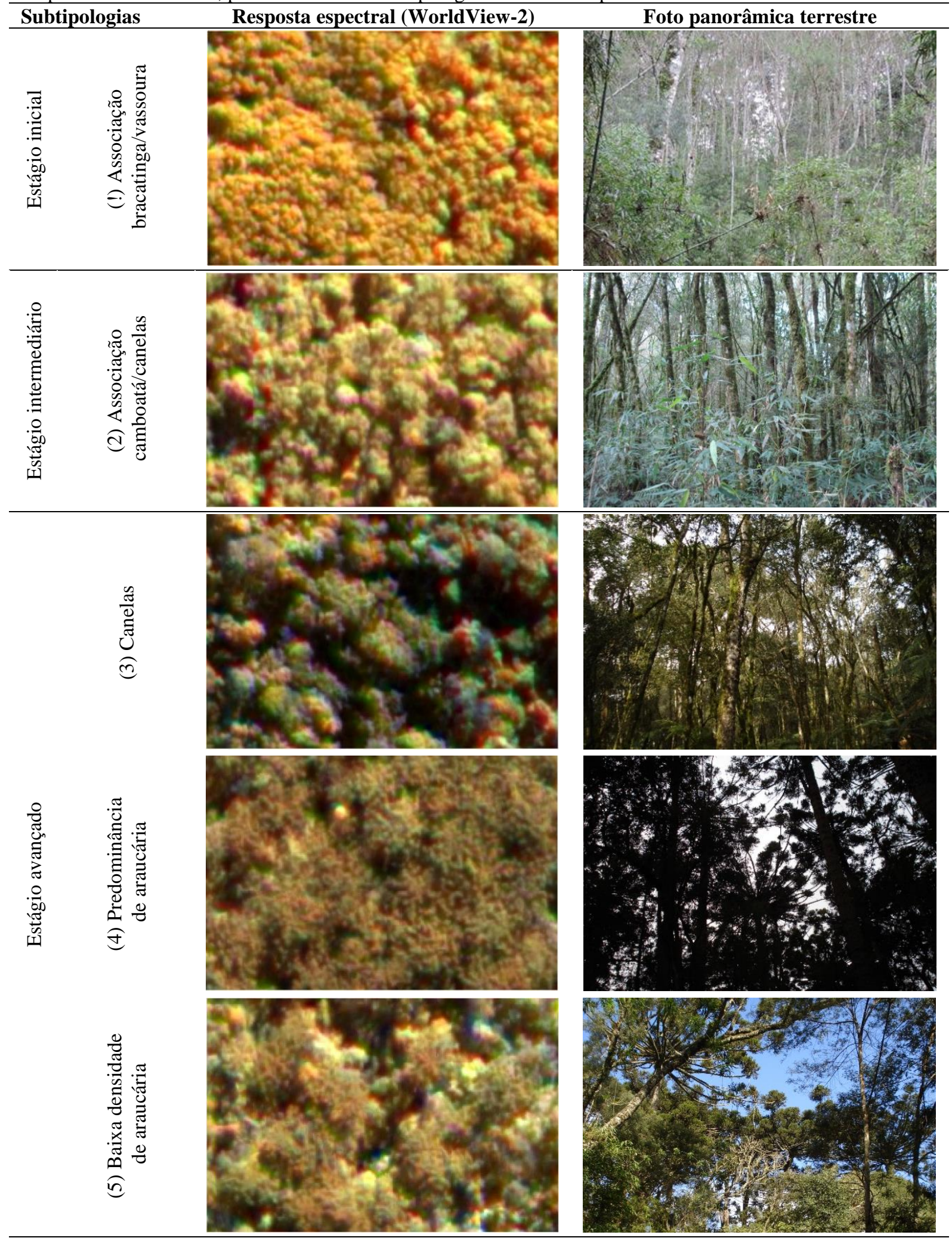


Tabela 3. Número de árvores por hectare (N.ha-1), por classe diamétrica, para as subtipologias mapeadas, de acordo com os dados auxiliares, obtidos por Beckert et al. (2014), para as áreas de predominância de araucária e Herrera et al. (2009), para as demais áreas.

\begin{tabular}{rrrrrr}
\hline \multirow{2}{*}{ Classe de DAP } & \multicolumn{5}{c}{ Número de árvores por hectare (N.ha-1) } \\
\cline { 2 - 6 } $10-29,99$ & $\mathbf{1}$ & $\mathbf{2}$ & $\mathbf{3}$ & $\mathbf{4}$ & $\mathbf{5}$ \\
$30-49,99$ & 123 & 503 & 336 & 51 & 353 \\
$50-69,99$ & 51 & 74 & 79 & 29 & 91 \\
$70-89,99$ & 14 & 15 & 10 & 17 & 22 \\
$90-109,99$ & 6 & 0 & 1 & 10 & 13 \\
$110-129,99$ & 0 & 0 & 6 & 6 & 4 \\
$130-149,99$ & 0 & 0 & 0 & 1 & 2 \\
\hline TOTAL & 0 & $\mathbf{5 9 4}$ & $\mathbf{4 5 6}$ & $\mathbf{1 6 9}$ & $\mathbf{4 8 4}$ \\
\hline
\end{tabular}

Em que: 1 - associação bracatinga/vassouras; 2 - associação camboatá/canelas; 3 - canelas; 4 - predominância de araucária; 5 - baixa densidade de araucária.

Tabela 4. Quantificação das classes mapeadas para a área de estudo.

\begin{tabular}{ccrrr}
\hline $\begin{array}{c}\text { Estágio de } \\
\text { desenvolvimento }\end{array}$ & Subtipologia & $\begin{array}{r}\mathbf{N}^{\circ} \text { de } \\
\text { polígonos. }\end{array}$ & $\begin{array}{r}\text { Área } \\
(\mathbf{h a})\end{array}$ & $\begin{array}{r}\text { Área } \\
(\boldsymbol{\%})\end{array}$ \\
\hline Inicial & Associação bracatinga/vassourão (1) & 50 & 151,35 & 12,64 \\
\hline Médio & Associação camboatá/canelas (2) & 39 & 169,67 & 14,17 \\
\hline \multirow{2}{*}{ Avançado } & Predominância de araucária (4) & 28 & 174,83 & 14,60 \\
& Baixa densidade de araucária (5) & 32 & 177,93 & 14,86 \\
& Canelas (3) & 28 & 453,89 & 37,92 \\
\hline & Agricultura/Fruticultura & 6 & 28,22 & 2,36 \\
Outros & Vegetação de solos úmidos (6) & 23 & 24,12 & 2,02 \\
& Várzea & 33 & 10,01 & 0,84 \\
& Estrada & 2 & 4,50 & 0,38 \\
& Solo exposto & 4 & 1,33 & 0,11 \\
& Lago & 2 & 1,18 & 0,10 \\
& Galpão & 1 & 0,01 & 0,00 \\
\hline & TOTAL & 248 & 1.197 & $100 \%$ \\
\hline
\end{tabular}

Unidades silviculturais (US)

Considerando que as US constituem o objeto de aplicação dos tratamentos silviculturais à floresta, nesse estudo derivaram-se das subtipologias mapeadas quatro US diferentes, agrupando-se as subtipologias com padrão estrutural e características próximas e que, portanto, podem receber as mesmas prescrições silviculturais de caráter geral (Figura 1).

I.FA (floresta com presença de araucária): corresponde a todos os lugares cujo dossel é caracterizado pela presença da espécie Araucaria angustifolia, independentemente de sua condição estrutural, composição e funcionamento atual. US composta pelas subtipologias "Predominância de araucária" e "Baixa densidade de araucária".

II.FE (floresta estruturada): corresponde às florestas com características de secundárias, mas que, já possuem estrutura vertical diversificada, mais ou menos desenvolvida, e riqueza de espécies arbóreas. É composta pelas áreas com dominância das subtipologias "Canelas" (estágio avançado de regeneração natural) e "Associação camboatá/canelas" (estágio médio), que, apesar de estarem classificadas como pertencentes a estágios de desenvolvimento distintos, apresentam estrutura semelhante.

III.FD (floresta degradada): US onde há dominância da subtipologia denominada “Associação bracatinga/vassourão". Sua estrutura encontra-se significativamente alterada, com subbosque dominado por espécies agressivas (Merostachys skvortzovii e indivíduos do gênero Chusquea spp.), que impedem o desenvolvimento da regeneração natural na área.

IV.SU (vegetação de solos úmidos): vegetação de pequeno porte, na maioria das vezes arbustiva, com características próprias de vegetação que se desenvolve em solos com umidade elevada.

Assim, tendo como base as US descritas, para cada talhão, no plano de ordenamento será definido o método silvicultural mais adequado, levando em conta sua composição de espécies, estrutura e seu estágio de desenvolvimento, com base nos objetivos do manejo (Rosot 2007). 


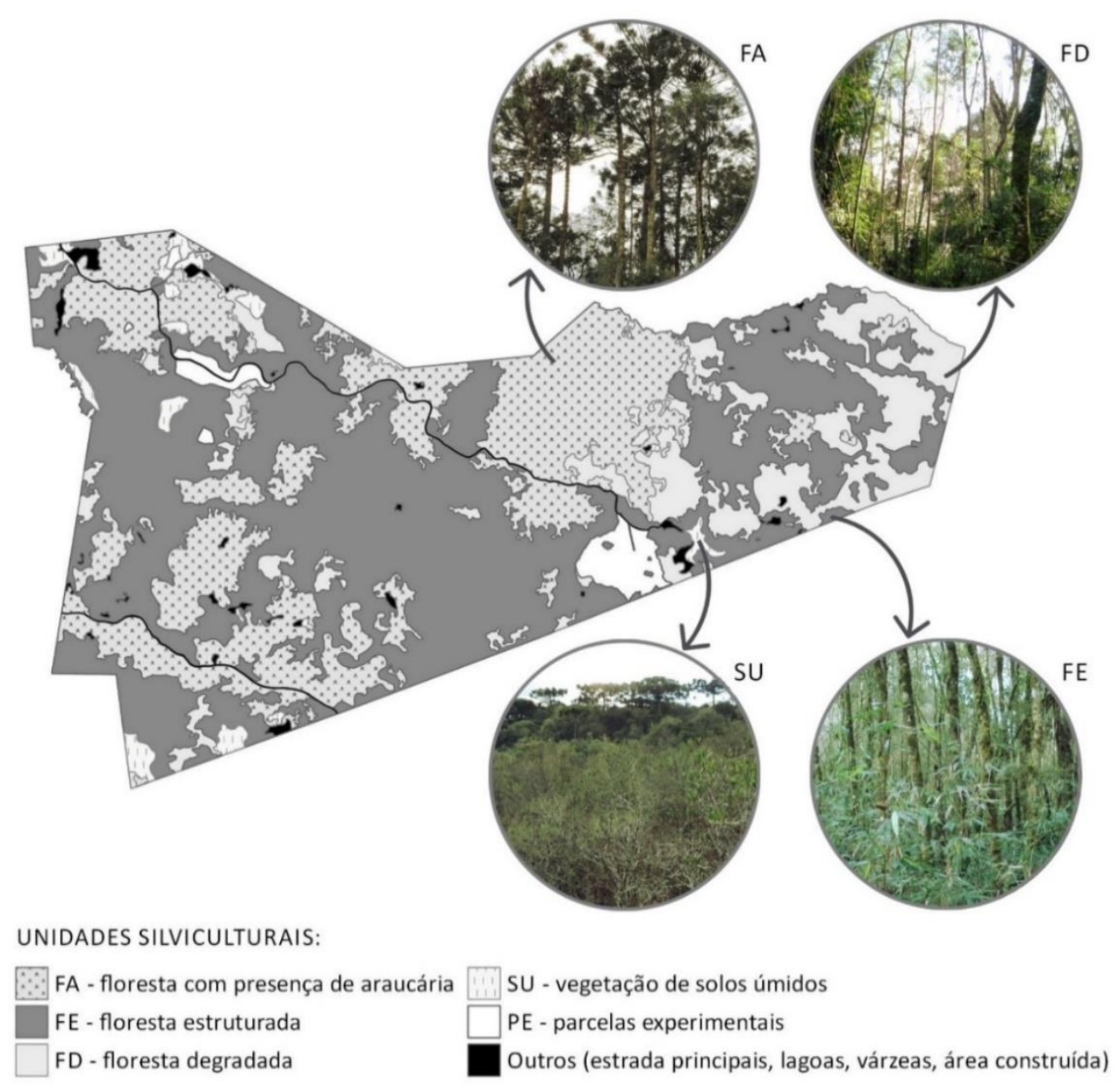

Figura 1. Mapa temático da distribuição das Unidades Silviculturais identificadas para a área de estudo, com respectivo detalhe de cada uma delas, ilustrado por fotografias panorâmicas terrestres.

\section{Talhonamento}

Cada talhão gerado a partir dos cruzamentos e posterior processo de agrupamento com fins operacionais, recebeu um código alfanumérico único e exclusivo, derivado da sigla da unidade silvicultural (FA, FE, FD ou SU) juntamente com o número de talhões para cada US. Assim, talhões definidos pela unidade silvicultural FA foram denominados com esta sigla acompanhada do número do talhão (1 até $\mathrm{n}$ ), por exemplo.
No caso de talhões correspondentes às zonas de uso restrito, o processo de nomenclatura deu-se da mesma maneira, adotando-se as siglas APP (áreas de proteção permanente) e PE (parcelas experimentais) para as áreas com restrições legais e operacionais de uso, respectivamente. Na Tabela 5 está apresentada a relação do número de talhões para cada US e sua respectiva área.

Tabela 5. Unidades Silviculturais (US) e zonas com restrição de uso definidas para a área de estudo e suas respectivas superfícies e número de talhões.

\begin{tabular}{cccc}
\hline \multirow{2}{*}{ Unidade Silvicultural (US) } & \multirow{2}{*}{$\mathbf{N}^{\circ}$ de Talhões } & \multicolumn{2}{c}{ Área } \\
\cline { 3 - 4 } & & Total (ha) & Total (\%) \\
\hline Floresta com araucária (FA) & 60 & 284,44 & 23,76 \\
Floresta estruturada (FE) & 76 & 441,32 & 36,87 \\
Floresta degradada (FD) & 26 & 133,84 & 11,18 \\
Vegetação de solos úmidos (SU) & 6 & 9,13 & 0,76 \\
\hline Subtotal & $\mathbf{1 6 8}$ & $\mathbf{8 6 8 , 7 3}$ & $\mathbf{7 2 , 5 8}$ \\
\hline Zonas com restrição legal de uso & 23 & 278,35 & 23,25 \\
Zonas com restrição operacional de uso & 60 & 44,22 & 3,69 \\
\hline Subtotal & $\mathbf{8 3}$ & $\mathbf{3 2 2 , 5 7}$ & $\mathbf{2 6 , 9 5}$ \\
\hline Outros (estradas/área construída) & - & 5,70 & 0,48 \\
\hline Total & $\mathbf{2 5 1}$ & $\mathbf{1 . 1 9 7}$ & $\mathbf{1 0 0 \%}$ \\
\hline
\end{tabular}

Adv For Sci, Cuiabá, v. 7, n. 2, p. 997-1008, 2020 
Proposição de tratamentos silviculturais gerais por unidade silvicultural (US)

A vegetação presente na EEEC apresenta uma grande diversidade de espécies e estruturas florestais. Essa informação traduziu-se na existência de numerosos talhões e seu respectivo agrupamento dentro de grupos fisionômicos, constituindo-se nas unidades silviculturais (US). Para cada US definiuse um regime silvicultural geral, que posteriormente poderá desdobrar-se no modelo de gestão de cada talhão especificamente, com base em suas características particulares. Nas Tabelas 6 e 7, na sequência, está apresentado o resumo dos regimes silviculturais propostos para cada unidade silvicultural presente na área de estudo.
Tratamento proposto para a floresta com presença de araucária $(F A)$

A estrutura das áreas com presença de Araucaria angustifolia é próxima à de uma floresta primária, onde são encontrados diversos indivíduos senis, e com características sanitárias indesejáveis, apresentando podridão no tronco. Em função disso, propõe-se um corte sanitário/aproveitamento destas árvores, promovendo a extração de material comercial antes de sua inviabilização, bem como a eliminação de árvores atacadas por insetos ou fungos, visando evitar que tais pragas se propaguem para outras árvores (Alonso 1996).

Tabela 6. Unidades Silviculturais (US) propostas e respectivos regimes gerais de manejo.

\begin{tabular}{|c|c|c|c|}
\hline $\mathbf{U S}$ & $\begin{array}{l}\text { Tipo de Talhão } \\
\text { (Subtipologias) }\end{array}$ & Objetivo do Manejo & Regime Silvicultura Geral \\
\hline \multirow{2}{*}{ FA } & $\begin{array}{l}\text { Predominância de } \\
\text { araucária }\end{array}$ & \multirow{2}{*}{$\begin{array}{l}\text { Manutenção do ecossistema, } \\
\text { mantendo-se uma proporção } \\
\text { entre o número de indivíduos } \\
\text { presentes nas classes diamétricas } \\
\text { sucessivas: floresta regulada } \\
\text { (produção sustentável). }\end{array}$} & \multirow{2}{*}{$\begin{array}{l}\text { Remoção de exemplares senis ou com } \\
\text { problemas fitossanitários; Intervenção por } \\
\text { meio do método de seleção com } \\
\text { aproveitamento comercial; Controle da } \\
\text { taquara. Monitoramento da regeneração } \\
\text { natural. }\end{array}$} \\
\hline & $\begin{array}{l}\text { Baixa densidade de } \\
\text { araucária }\end{array}$ & & \\
\hline \multirow[t]{2}{*}{ FE } & Canelas & \multirow{2}{*}{$\begin{array}{l}\text { Preparação da floresta para a } \\
\text { futura produção de produtos e } \\
\text { serviços. }\end{array}$} & \multirow{2}{*}{$\begin{array}{l}\text { Cortes de melhoramento; Controle da } \\
\text { taquara; Plantios de adensamento e } \\
\text { enriquecimento, } \\
\begin{array}{l}\text { desenvolvimento do sisando } \\
\text { produção de madeira e subprodutos } \\
\text { (produtos não madeireiros). }\end{array} \\
\end{array}$} \\
\hline & $\begin{array}{c}\text { Associação } \\
\text { camboatá/canelas }\end{array}$ & & \\
\hline FD & $\begin{array}{c}\text { Associação } \\
\text { bracatinga/vassourão }\end{array}$ & Restauração do ecossistema. & $\begin{array}{l}\text { Limpeza para o controle da taquara; } \\
\text { Manejo da espécie Mimosa scabrella por } \\
\text { meio do raleio; Intensificação do uso de } \\
\text { sistemas de recomposição; } \\
\text { Enriquecimento. }\end{array}$ \\
\hline SU & $\begin{array}{l}\text { Vegetação de solos } \\
\text { úmidos }\end{array}$ & $\begin{array}{l}\text { Serviços ambientais. Sem ações } \\
\text { de manejo propostas no } \\
\text { momento. }\end{array}$ & $\begin{array}{l}\text { Proteção. Sem regime proposto no } \\
\text { momento. }\end{array}$ \\
\hline
\end{tabular}

Em que: FA - floresta com presença de araucária; FE - floresta estruturada; FD - floresta degradada e; SU vegetação de solos úmidos.

Tabela 7 - Zonas com restrições de uso e respectivos regimes gerais de manejo propostos.

\begin{tabular}{|c|c|c|c|}
\hline Zona & Tipo de Restrição & Objetivo do Manejo & Regime Silvicultural Geral \\
\hline APP & Legal & $\begin{array}{l}\text { Manutenção do ecossistema. } \\
\text { Serviços ambientais. Obtenção e } \\
\text { aproveitamento de produtos } \\
\text { florestais não madeireiros } \\
(P F N M) .\end{array}$ & $\begin{array}{l}\text { Coleta de produtos florestais não } \\
\text { madeireiros, como folhas, sementes e } \\
\text { frutos. Instalação de caixas de abelhas, } \\
\text { visando o aproveitamento do potencial } \\
\text { apícola de diversas espécies da FOM. }\end{array}$ \\
\hline PE & Operacional & $\begin{array}{l}\text { Diferente para cada talhão. } \\
\text { Depende do objetivo de cada } \\
\text { área experimental. }\end{array}$ & $\begin{array}{l}\text { Diferente para cada talhão. Depende do } \\
\text { objetivo de cada área experimental. }\end{array}$ \\
\hline
\end{tabular}

Em que: APP - áreas de preservação permanente e; PE - parcelas experimentais. 
Os dados das parcelas permanentes, por meio da variável área basal (41,45 m².ha-1), indicam que a floresta já atingiu seu clímax, e encontra-se em fase de estagnação do crescimento. Trabalhando na mesma floresta do estudo, Beckert et al. (2014) constataram redução média constante para esta variável, bem como índices de mortalidade que superam o recrutamento de indivíduos na área (dentro de um período de nove anos).

São necessárias, portanto, ações de manejo visando a manutenção desta floresta em um estado produtivo e sustentável. Neste grupo de talhões acredita-se que o sistema silvicultural de seleção seja uma alternativa potencial a ser empregada para esta subtipologia, pois é especialmente indicado para estrutura de floresta alta multiânea (Rosot 2007), caracterizando-se pela seleção de plantas de modo que haja uma série contínua de classes de idade na floresta e um contínuo recrutamento, advindo da regeneração natural.

Assim, para esta US, recomenda-se o corte seletivo de $20 \%$ da área basal, por classe de DAP acima de $40 \mathrm{~cm}$ para os indivíduos de Araucaria angustifolia e de $20 \%$ da área basal por classe de DAP das demais espécies. Comparando diferentes percentuais de exploração em FOM secundária, em estágio avançado de regeneração natural, Longhi et al. (2018) constataram maiores índices de recuperação no tratamento com remoção de $20 \%$ da área basal, principalmente nas classes iniciais de DAP, que representam o futuro da floresta; verificaram, também, neste mesmo tratamento, os maiores incrementos periódicos anuais (IPA) tanto em área basal quanto em volume.

Com este percentual de remoção, os autores citados afirmaram que o ciclo de regeneração para a recuperação do estoque inicial em volume é de oito anos. No ensaio realizado por esses autores, o tratamento testemunha (sem intervenções silviculturais) apresentou as mesmas características que a floresta da EEEC apresenta hoje: um decréscimo de indivíduos, com taxas maiores para mortalidade do que para o recrutamento, ressaltando a necessidade de intervenções, uma vez que estes fragmentos possivelmente estão superestocados (Longhi et al. 2018).

Adicionalmente, a aplicação de qualquer ação que ocasione a abertura do dossel na EEEC deve vir acompanhada de ações de controle e remoção dos indivíduos de Merostachys skvortzovii e do gênero Chusquea spp, que podem estar associadas como espécie inibidoras do crescimento da regeneração natural na Floresta Ombrófila Mista. Além disso, recomenda-se, para este grupo de talhões, o monitoramento da regeneração natural após a aplicação dos tratamentos silviculturais propostos, mantendo-se uma área testemunha para comparação.

Resultados de estudos já realizados dentro desta US indicam que o recrutamento de novos indivíduos de Araucaria angustifolia é baixo ou quase inexistente (Lingner et al. 2007; Beckert et al. 2014), não apresentando indivíduos no estrato inferior. Isso indica que a sua regeneração está sendo comprometida devido ao avanço das folhosas sendo este fato comum em florestas em estágio avançado (Lingner et al. 2007), ou pela presença de Merostachys skvortzovii e Chusquea spp. no subbosque. Espera-se que os tratamentos propostos, bem como, o controle da taquara, promovam abertura suficiente para o recrutamento e regeneração de espécies de interesse, por vias naturais (Santos et al. 2015), não sendo necessário o enriquecimento destas áreas.

\section{Tratamento proposto para a floresta estruturada} (FE)

Para estas áreas recomenda-se a diminuição da densidade de indivíduos sem interesse para o manejo, de forma gradativa, evitando a abertura do dossel em grande escala. Dessa forma minimiza-se os impactos causados às remanescentes com a derrubada de indivíduos de maiores dimensões. A aplicação dos denominados cortes de melhoramento visa eliminar a competição vertical produzida por exemplares de maior tamanho, pertencentes a espécies que não apresentam interesse econômico (Alonso 1996).

O corte de melhoramento é ainda indicado para florestas que tenham sofrido exploração seletiva no passado (Alonso 1996), como é o caso da floresta presente na EEEC. A limpeza e manutenção da taquara também são atividades fundamentais nessa US. Após esta etapa, o sub-bosque mostra-se propício para a produção de erva-mate (Ilex paraguariensis A.St.-Hil.) sob cobertura, por meio do adensamento, mediante o plantio de mudas produzidas em viveiro, podendo ser plantada à sombra de outras árvores, crescendo bem nas associações dos estágios sucessionais mais avançados da FOM (Marques et al 2012).

Tratamento proposto para a floresta degradada (FD)

A limpeza e o controle da taquara são as principais medidas a serem consideradas para o manejo desta US. Mimosa scabrella, presente em diversos talhões, constitui formações quase homogêneas, com presença massiva da Merostachys skvortzovii em seu sub-bosque, o que vem freando o processo de desenvolvimento natural dessa vegetação e impedindo a sua evolução para um estágio mais bem desenvolvido.

Recomenda-se, para estas áreas, após o controle da Merostachys skvortzovii, o manejo da Mimosa scabrella, acompanhado de um plantio de adensamento e enriquecimento em linhas, utilizando-se espécies de interesse econômico e ecológico, como Araucaria angustifolia, Ocotea porosa, Ocotea odorifera (Vell.) Rohwer e Cedrela 
fissilis Vell., por exemplo, visando a exploração dessa madeira futuramente.

Para os talhões em processo de transição do estágio de regeneração - onde a dominância das formações homogêneas constituídas pela bracatinga não é tão evidente, sendo entremeadas por indivíduos de outras espécies - é necessário eliminar gradativamente as espécies que não são interessantes para o manejo. Dessa forma, propicia-se melhores condições às remanescentes com maior valor econômico que podem existir nessas áreas, além de manter a limpeza do sub-bosque e realizar a condução destas espécies de interesse para o manejo.

Tratamento proposto para as zonas com restrições legais de uso (APP)

Para os talhões localizados em APPs, recomenda-se o manejo visando a obtenção de produtos florestais não madeireiros (PFNMs). Em inventário realizado por Sanquetta et al. (2010) em uma área de Floresta Ombrófila Mista foram identificadas 134 espécies vegetais, sendo que mais de $53 \%$ caracterizavam-se como fornecedoras de produtos não madeireiros, validando o potencial de fornecimento de PFNM para estas áreas. Os autores apontaram, ainda, algumas espécies como "prioritárias", por se destacarem no que diz respeito ao fornecimento de PFNM na Floresta Ombrófila Mista. Entre elas se encontram: Schinus terebinthifolia Raddi, Ilex paraguariensis, Cedrela fissilis, Luehea divaricata Mart. \& Zucc.. São ainda encontradas algumas espécies frutíferas na área de estudo, como Campomanesia xanthocarpa (Mart.) O.Berg, Psidium cattleyanum Sabine e Inga sp., que são bastante empregadas como alimento in natura ou no preparo de geleias e doces (Sanquetta et al. 2010).

Outra característica passível de ser aproveitada em diversas espécies é seu potencial apícola. A flora apícola - nome dado ao conjunto de plantas que fornecem alimento às abelhas em uma determinada região - é um dos fatores determinantes para a eficiência da atividade apícola, seja qual for a localidade (Marochi et al. 2013). Na área de estudo as espécies identificadas com tal potencialidade são: Schinus terebinthifolia, Piptocarpha angustifolia Dusén ex Malme, Vernonanthura discolor (Spreng.) H.Rob., Gymnanthes klotzschiana Müll.Arg., Ocotea porosa, Cedrela fissilis, Mimosa scabrella, Campomanesia xanthocarpa, Cupania vernalis Cambess., Luehea divaricata, entre outras. Sendo assim, sugere-se como uma alternativa na utilização das áreas de APP, como atividade de baixo impacto, a instalação de caixas de abelhas e seu manejo - o indicativo de uma colmeia por hectare é apontado por Wolff (2010) como adequado para um apiário ser produtivo.

\section{Considerações finais}

As diferentes subtipologias observadas na área de estudo, por representarem as mesmas variações que ocorrem ao longo do território ocupado pela FOM, apresentam também os mesmos desafios, tanto para a sua manutenção como para a sua recuperação. Dessa forma, os regimes silviculturais gerais aqui apresentados, podem desdobrar-se em um modelo de gestão para fragmentos de Floresta Ombrófila Mista com características semelhantes com base em suas características particulares.

\section{Referências}

Alboreca AR (2016) El reto de la ordenación de los montes privados en España. Cuadernos de la Sociedad Española de Ciencias Forestales, 39:275297. doi: https://doi.org/10.31167/csef.v0i39.17468

Alonso AV (1996) Los tratamientos silviculturales. $1^{\text {th }}$ Edition. Santiago: Universidad de Chile, Faculdad de Ciencias Agrarias y Forestales. 243p.

Basso CMG (2010) A araucária e a paisagem do planalto sul brasileiro. Revista de Direito Público, $5(2): 1-11$.

Beckert SM, Rosot MAD, Rosot NC (2014) Crescimento e dinâmica de Araucaria angustifolia (Bert.) O. Ktze. em fragmento de Floresta Ombrófila Mista. Scientia Forestalis, 42(102):209-218.

Cochmanski JC (2015) Estruturação de bases temáticas como subsídio à proposição de tratamentos silviculturais para fragmentos de Floresta Ombrófila Mista. Dissertação, Universidade Estadual do Centro Oeste. 137p.

Comunidad de Madrid (2010) Instrucciones de Ordenación de Montes de la Comunidad de Madrid. Madrid: Consejería de Medio Ambiente y Ordenación del Territorio. 168p.

Conama. Conselho Nacional do Meio Ambiente. (1993) Resolução n ${ }^{\circ}$ 10, de 01 de outubro de 1993. Diário Oficial [da] República Federativa do Brasil, Brasília, DF, 209:16497-16498.

Conama. Conselho Nacional do Meio Ambiente (1994) Resolução nº. 02, de 18 de março de 1994. Diário Oficial [da] República Federativa do Brasil, Brasília, DF, 059:4513-4514. (a)

Conama. Conselho Nacional do Meio Ambiente. (1994) Resolução nº. 04, de 04 de maio de 1994. Diário Oficial [da] República Federativa do Brasil, Brasília, DF, 114: 8877-8878. (b)

Conama. Conselho Nacional do Meio Ambiente (2001) Resolução nº. 278, de 24 de maio de 2001. Diário Oficial [da] República Federativa do Brasil, Brasília, DF, 138:51-52. 
EUROPARC-España (2013) Proyectos de ordenación de montes: Herramientas para la conservación en los espacios protegidos. Manual 11 - Programa de trabajo para las áreas protegidas 20092013. Madrid: Fundación Interuniversitaria Fernando González Bernáldez. 84p.

Fantini AC, Siminski A, Gaio MF (2016) Madeira de florestas secundárias em SC: nova fonte de renda para os agricultores. Agropecuária Catarinense 29(2):15-18.

Fundação SOS Mata Atlântica (2018) Atlas dos Remanescentes Florestais da Mata Atlântica período 2016-2017. Relatório Técnico. São Paulo: ArcPlan. 63p.

Gotarredona CDC, Garcia RO (2008) Aplicación del método de ordenación por rodales en el monte "Pinar del Rey y Dehesilla”, T. M. San Roque (Cádiz). Cuadernos de la Sociedad Española de Ciencias Forestales, 21: 67-72.

Grau PV, Nicolau MP (2007) Utilización del método de ordenación por rodales para compatibilizar la gestión forestal y la conservación de la biodiversidad. Cuadernos de la Sociedad Española de Ciencias Forestales, 21:125-133.

Grau PV, Nicolau MP (2008) La Ordenación Por Rodales en Cataluña: Algunas Experiencias y Valoraciones. Cuadernos de la Sociedad Española de Ciencias Forestales, 27: 29-34.

Herrera HAR, Rosot NC, Rosot MAD, de Oliveira YMM (2009) Análise florística e fitossociológica do componente arbóreo da Floresta Ombrófila Mista presente na Reserva Florestal Embrapa/Epagri, Caçador, SC - Brasil. Floresta, 39(3):485-500. doi: http://dx.doi.org/10.5380/rf.v39i3.15349

Hess AF, Calgarotto AR, Pinheiro R, Wanginiak TCR (2010) Proposta de manejo de Araucaria angustifolia utilizando o quociente de Liocourt e análise de incremente, em propriedade rural no Município de Lages, SC. Pesquisa Florestal Brasileira, 30(64):337-345. doi: 10.4336/2010.pfb.30.64.337

Kellermann B (2011) Monitoramento da regeneração natural em fragmento de floresta ombrófila mista e morfoanatomia de plântulas $e$ tirodendros de Piptocarpha angustifolia Dusén ex Malme (Asteraceae). Dissertação, Universidade Federal do Paraná. 141p.

Lingner DV, de Oliveira YMM, Rosot NC, Dlugosz FL (2007) Caracterização da estrutura e da dinâmica de um remanescente de Floresta com Araucária no
Planalto Catarinense. Pesquisa Florestal Brasileira, 0(55):55-66.

Longhi RV, Schneider PR, Longhi SJ, Marangon GP, Costa EA (2018) Growth dynamics of araucaria after management intervention in natural forest. Floresta e Ambiente, 25(2): e20150264. doi: http://dx.doi.org/10.1590/2179-8087.026415

Marques AC, Mattos AG, Bona LC, dos Reis MS (2012) Florestas Nacionais e desenvolvimento de pesquisas: o manejo da erva-mate (Ilex paraguariensis A.St.-Hil.) na Flona de Três Barras/SC. Biodiversidade Brasileira, 2(2):4-17.

Marochi MR, Oliveira Filho PC, Gomes GS, Machado ALF (2013) Efeitos do uso da terra sobre a produção apícola com destaque para estágios distintos de Floresta Ombrófila Mista. Floresta e Ambiente, 20(1):45-54. doi: http://dx.doi.org/10.4322/floram.2012.074

Molina JMG, Nicolau MP, Gray PV (2011) Manual de ordenación por rodales.Gestión multifuncional de los espacios forestales. $2^{\text {th }}$ Edition. Catalunya: Centre Tecnològic Forestal de Catalunya. 209p.

Nasi R, Frost PGH (2009) Sustainable forest management in the tropics: is everything in order but the patient still dying? Ecology and Society, $14(2): 40-52$.

Piazza GE, Zambiazi DC, Correia J, Fantini AC (2017) Regeneração natural de espécies madeireiras na floresta secundária da Mata Atlântica. Advances in Forestry Science, 4(2):99-105. doi: http://dx.doi.org/10.34062/afs.v4i2.4034

Rodríguez FMH, Palá JAO, Oar BA, Tavira SC, Rebollo PF, Diaz RZ (2004) Manual de ordenación de montes de Andalucía. Sevilla: Consejería de Medio Ambiente/Junta de Andalucía. 357p.

Romero FR (2016) Proyecto de Ordenación del MUP N ${ }^{\circ} 12$ "Vega Tajo" perteneciente a la cuidad y comunidad de Albarracín. In: Curso de Redacción de Instrumentos de Gestión Forestal en Aragon, Zaragoza, Spain.

Rosot MAD (2007) Manejo florestal de uso múltiplo: uma alternativa contra a extinção da Floresta com Araucária? Pesquisa Florestal Brasileira, 55(1):75-85.

Sánchez-Palencia SM, Rodríguez AP, Balteiro LD, de Toda SSM (2011) Manual para la redacción de instrumentos de gestión forestal sostenible en Castilla-La Mancha. Serie Forestal $\mathrm{N}^{\circ} 8$. Guadalajara. España: Junta de Comunidades de Castilla-La Mancha/Consejería de Agricultura y 
Medio Ambiente/Dirección General de Politica Forestal. 188p.

Sanquetta CR, Fernandes LAV, Miranda DLC, Mognon F (2010) Inventário de plantas fornecedoras de produtos não madeireiros da Floresta Ombrófila Mista no estado do Paraná. Scientia Agraria, 11(5):359-369. doi: http://dx.doi.org/10.5380/rsa.v11i5.20222

Santos KF, Ferreira TS, Higushi P, da Silva AC, Vandresen PB, da Costa A, Spada G, Schmitz V, de Souza F (2015) Regeneração natural do componente arbóreo após a mortalidade de um maciço de taquara em um fragmento de Floresta Ombrófila Mista em Lages - SC. Ciência Florestal, 25(1):107-117. doi: http://dx.doi.org/10.5902/1980509817467

Speidel H (1893) Aus Theorie und praxis der Forstbetriebseinrichtung. Allgemeine Forst und Jagdzeitschrift, 69:145-181.

Venturoli F, Franco AC, Fagg CW (2015) Tree diameter growth following silvicultural treatments in a semi-deciduous secondary forest in central Brazil. Cerne, 21(1):117-123. doi: http://dx.doi.org/10.1590/01047760201521011204

Wolff, LF (2010) ABC da Agricultura Familiar: Como instalar colmeias. Brasília/DF: Embrapa Informação Tecnológica. 59p. 